\title{
RESEARCH
}

Open Access

\section{Examining purchasing reforms towards universal health coverage by the National Hospital Insurance Fund in Kenya}

\author{
Rahab Mbau ${ }^{1 *}$ D, Evelyn Kabia', Ayako Honda², Kara Hanson ${ }^{3}$ and Edwine Barasa ${ }^{1,4}$
}

\begin{abstract}
Background: Kenya has prioritized the attainment of universal health coverage (UHC) through the expansion of health insurance coverage by the National Hospital Insurance Fund (NHIF). In 2015, the NHIF introduced reforms in premium contribution rates, benefit packages, and provider payment methods. We examined the influence of these reforms on NHIF's purchasing practices and their implications for strategic purchasing and health system goals of equity, efficiency and quality.

Methods: We conducted an embedded case study with the NHIF as the case and the reforms as embedded units of analysis. We collected data at the national level and in two purposively selected counties through 41 in-depth interviews with health financing stakeholders, facility managers and frontline providers; 4 focus group discussions with $51 \mathrm{NHIF}$ members; and, document reviews. We analysed the data using a Framework approach.

Results: The new NHIF reforms were characterized by weak purchasing actions. Firstly, the new premium contribution rates were inadequately communicated and unaffordable for certain citizen groups. Secondly, while the new benefit packages were reported to be based on service needs, preferences and values of the population, they were inadequately communicated and unequally distributed across different citizen groups. In addition, the presence of service delivery infrastructure gaps in public healthcare facilities and the pro-urban and pro-private distribution of contracted health facilities compromised delivery of, and access to, these new services. Lastly, the new provider payment methods and rates were considered inadequate, with delayed payments and weak links to financial accountability mechanisms which compromised their ability to incentivize equity, efficiency and quality of healthcare delivery.

Conclusion: While NHIF sought to expand population and service coverage and reduce out-of-pocket payments with the new reforms, weaknesses in the reforms' design and implementation limited NHIF's purchasing actions with negative implications for the health system goals of equity, efficiency and quality. For the reforms to accelerate the country's progress towards UHC, policy makers at the NHIF and, national and county government should make deliberate efforts to align the design and implementation of such reforms with strategic purchasing actions that are aimed at improving health system goals.
\end{abstract}

Keywords: Universal health coverage, Strategic purchasing, Purchasing reforms, National Hospital Insurance Fund, Equity, Efficiency, Quality

\footnotetext{
* Correspondence: RMbau@kemri-wellcome.org

'Health Economics Research Unit, KEMRI Wellcome Trust Research

Programme, P.O. BOX 43640-00100, Nairobi, Kenya

Full list of author information is available at the end of the article
}

C The Author(s). 2020 Open Access This article is distributed under the terms of the Creative Commons Attribution 4.0 International License (http://creativecommons.org/licenses/by/4.0/), which permits unrestricted use, distribution, and reproduction in any medium, provided you give appropriate credit to the original author(s) and the source, provide a link to the Creative Commons license, and indicate if changes were made. The Creative Commons Public Domain Dedication waiver (http://creativecommons.org/publicdomain/zero/1.0/) applies to the data made available in this article, unless otherwise stated. 


\section{Background}

Health financing reforms for universal health coverage (UHC) in low and middle-income countries (LMICs) have mainly focused on two health financing functions: revenue collection and pooling [1]. There is, however, increasing global recognition of the importance of the third healthcare financing function of purchasing as an important policy tool towards achieving UHC [2-4]. UHC emphasizes financial protection and equitable access to goodquality health services according to one's healthcare needs [5]. Purchasing, which refers to the transfer of pooled resources to healthcare providers for the provision of healthcare services $[6,7]$, provides a critical link between healthcare financing and healthcare service delivery, and facilitates efficiency, equity and quality in health systems performance [2]. Purchasing can either be passive or strategic. Passive purchasing is the transfer of pooled resources to providers based on historical or predetermined budgets while strategic purchasing involves a deliberate process of determining which services to buy, from who and at what cost with the aim of maximizing health system performance $[2,6,8]$.

Kenya, a lower middle-income country, has prioritized the attainment of UHC by 2022 through the expansion of health insurance coverage by the $\mathrm{Na}$ tional Hospital Insurance Fund (NHIF) [9]. Current NHIF coverage is $15.8 \%$, which is equivalent to over
$80 \%$ of the total population with any form of health insurance in Kenya [10]. NHIF is a state corporation whose mandate is to provide health insurance to its members and their dependents [11, 12]. It is one of the healthcare purchasers and the largest health insurer in Kenya with several health insurance schemes (Table 1). Other healthcare purchasers in Kenya include the national government, the county governments, households and private health insurers including community-based health insurers [23, 24].

Previous empirical work on purchasing arrangements in Kenya focused on the purchasing practices of the NHIF, county governments, private and community-based health insurers [23-25]. The previous study on NHIF, conducted in 2014, aimed to describe and analyse the purchasing arrangements between NHIF and the government, healthcare providers and citizens [25]. That study, which was conducted before the introduction of the new NHIF reforms described further below, identified significant weaknesses in the purchasing actions between the NHIF as a purchaser and the government, citizens and healthcare providers [25]. For example, along the NHIF-government axis, the absence of an overarching regulatory framework for health service purchasing undermined NHIF's performance. Along the NHIFcitizen axis, the process for service entitlement design was delinked from citizen preferences, needs and

Table 1 Health insurance schemes under the NHIF

\begin{tabular}{|c|c|c|}
\hline Type of scheme & Premium contribution & Population covered \\
\hline Civil servants scheme $e^{a}[13,14]$ & Mandatory/automatic & $\begin{array}{l}\text { Civil servants in the national and county governments, their declared spouse and up to } \\
5 \text { children of up to } 21 \text { years of age or } 25 \text { years if enrolled in fulltime formal education } \\
{[13,14]}\end{array}$ \\
\hline County government scheme ${ }^{a}[15]$ & Mandatory/automatic & $\begin{array}{l}\text { Employees of County governments that have contract arrangements with the NHIF, their } \\
\text { declared spouse and up to } 5 \text { children of up to } 21 \text { years of age or } 25 \text { years if enrolled in } \\
\text { fulltime formal education [16] }\end{array}$ \\
\hline $\begin{array}{l}\text { Parastatal/ private company } \\
\text { schemes }^{\mathrm{a}}[15]\end{array}$ & Mandatory/automatic & $\begin{array}{l}\text { Employees of parastatals or private firms that have contract arrangements with NHIF, } \\
\text { their declared spouse and up to } 5 \text { children of up to } 21 \text { years of age or } 25 \text { years if } \\
\text { enrolled in fulltime formal education [16] }\end{array}$ \\
\hline $\begin{array}{l}\text { National police and Kenya } \\
\text { Prisons }{ }^{a}[17,18]\end{array}$ & Mandatory/automatic & $\begin{array}{l}\text { Kenya Police Force, Administration police, officers in the Criminal Investigations } \\
\text { Department, prisons and other security related officers, their declared spouse and up to } \\
5 \text { children up to } 21 \text { years of age or } 25 \text { years if enrolled in fulltime formal education [16] }\end{array}$ \\
\hline $\begin{array}{l}\text { Secondary schools' scheme } \\
\text { [EduAfya] }[12,19,20]\end{array}$ & Mandatory/automatic & All students in public secondary schools in Kenya \\
\hline National scheme [21] & $\begin{array}{l}\text {-Mandatory for formal } \\
\text { sector workers, } \\
\text {-Voluntary for informal } \\
\text { sector workers }\end{array}$ & $\begin{array}{l}\text { Any person who is a resident of the republic of Kenya, who is self-employed or in the in- } \\
\text { formal sector, their declared spouse (s) and children up to the age of } 18 \text { years }\end{array}$ \\
\hline $\begin{array}{l}\text { Health Insurance Subsidy for the } \\
\text { Poor [HISP] Scheme [22] }\end{array}$ & Mandatory/automatic & $\begin{array}{l}\text { Households with orphans and vulnerable children; poor elderly; and/ or persons, persons } \\
\text { with disabilities and destitute families }\end{array}$ \\
\hline $\begin{array}{l}\text { Linda Mama Free maternity } \\
\text { scheme }[15]\end{array}$ & Mandatory/automatic & All pregnant women who are Kenyan Citizens \\
\hline
\end{tabular}

a The civil servants scheme, the national police and prisons service scheme, the county government schemes, and the parastatal/ private company schemes form the enhanced benefits schemes because they offer comprehensive medical insurance covers [16]. 
feedback. Along the NHIF-provider axis, weaknesses included inadequate use of quality and efficiencyimprovement strategies such as treatment guidelines and generic essential medicines lists [25].

\section{Recent reforms by the NHIF}

In 2015, NHIF introduced several linked reforms aimed at accelerating the country's progress towards UHC. First, the NHIF revised premium contribution rates upwards (Table 2) with effect from April 1st' 2015 [26]. This was done to cater for the rising cost of healthcare and to enable expansion of its benefits package [27].

Second, following the upward revision of the premiums, the NHIF expanded its benefit cover to include outpatient services for the national scheme (previously, the NHIF covered outpatient services for beneficiaries of the enhanced schemes and HISP only) and specialised services for all the NHIF schemes [22]. The specialised services offered include: renal dialysis; kidney transplant; radiology package (magnetic resonance imaging (MRI) and computed tomography (CT)); oncology package (chemotherapy and radiotherapy); chronic illness (diabetes and hypertension); maternity package (normal and caesarean section); rehabilitation package (drug and substance abuse); specialised laboratory tests; surgical package (major, minor and specialised); foreign treatment; and emergency evacuation services [22].

Third, the NHIF introduced new provider payment methods and rates for the new outpatient and specialised benefit packages [22]. It introduced capitation for outpatient services and, case-based and fee-for- service payments for the specialised services. It also revised the per diem rates for inpatient care (already part of the old benefit package) upwards from between KES 600 and 2400 (USD 6-24) [28] to between KES 1500 and 4000 (USD 15-40) per day for the lowest-level and highest-level hospitals, respectively [22]. Table 3 provides a summary of the different payment methods and rates under the NHIF.
These three purchasing reforms are UHC-inspired reforms as they seek to expand the benefit package and population covered while reducing the costs of out-of-pocket (OOP) payments associated with the use of these services [29] with important implications for the health systems goals of equity, efficiency and quality [30]. These reforms, separately and together, have the potential to influence the purchasing practices of the NHIF. The aim of this study is to examine the influence of the purchasing reforms on NHIF's purchasing practices and the implications of this for strategic purchasing and health system goals of equity, efficiency and quality.

\section{Methods}

\section{Study design}

We employed an embedded case study design [31] with the NHIF as the case and the different reforms as the embedded units of analysis. A case study is an empirical enquiry that investigates a real-life phenomenon through a detailed contextual analysis of the phenomenon [31]. A case study approach is appropriate for this study because it provides a structured yet flexible approach to data collection and analysis using multiple sources of evidence [31, 32].

\section{Study framework}

We applied the Resilient and Responsive Health Systems (RESYST) conceptual framework for purchasing (Fig. 1). This framework outlines the key strategic purchasing actions that characterise the three purchaser relationships: Government and purchasers, purchasers and healthcare providers, and citizens and purchasers [2]. For this study, we adapted the RESYST conceptual framework by including the NHIF's purchasing reforms and potential implications of the reforms on the health systems goals mediated through the key purchasing actions (Fig. 1). In this study, the purchaser is the NHIF while the 1) government, 2) providers and 3) citizens are represented by the 1) Ministry of

Table 2 NHIF premiums before and after the 2015 reform in Kenya shillings (KES)/ United States Dollars (USD)

\begin{tabular}{llll}
\hline Type of sector & Monthly salary range 1USD = KES 100) & $\begin{array}{l}\text { Monthly premium before the } \\
\text { reform }\end{array}$ & $\begin{array}{l}\text { Monthly premium after the } \\
\text { reform }\end{array}$ \\
\hline Formal sector & KES 1000-5999 (USD 10-59) & KES 30-120 (USD 0.3-1.2) & KES 150 (USD 1.5) \\
& KES 6000-7999 (USD 60-79) & KES 140-160 (USD 1.4-1.6) & KES 300 (USD 3) \\
& KES 8000-11,999 (USD 80-119) & KES 180-240 (USD 1.8-2.4) & KES 400 (USD 4) \\
& KES 12,000-14,999 (USD 120-149) & KES 260-300 (USD 2.6-3) & KES 500 (USD 5) \\
& KES 15,000 and above (USD 150 and & KES 320 (USD 3.2) & KES 600-1700 (USD 6-17) \\
above) & Ko salary ranges. & KES 160 (USD 1.6) & KES 500 (USD 5) \\
$\begin{array}{l}\text { Informal sector (self- } \\
\text { employed) }\end{array}$ & & &
\end{tabular}


Table 3 NHIF Provider payment methods and rates [22]

\begin{tabular}{ll}
\hline $\begin{array}{l}\text { Provider } \\
\text { payment } \\
\text { method }\end{array}$ & Healthcare benefit package \\
\hline Capitation & Outpatient services for national scheme members
\end{tabular}

Reimbursement rate

$1 \mathrm{USD}=100 \mathrm{KES}$

Capitation Outpatient services for national scheme members

payment

Renal dialysis (pre-dialysis, intra-dialysis and post-dialysis care)

Kidney transplant package- surgical costs and duration of hospitalization

Maternity package for National scheme

Maternity package for the Free maternity program

Oncology package- treatment for cancer patients using radiotherapy or chemotherapy case management

Surgical package (covers even cancer surgeries)

Rehabilitation package (drug and substance abuse)

Fee-for-service

Radiology package

Dental cover (Enhanced schemes only) [16]

Optical cover (Enhanced schemes only) [16]

Maternity package for Enhanced schemes

Inpatient care (medical and surgical conditions that require admission) for Enhanced scheme members of higher job groups ( $L$ and above or its equivalent) [14]
KES 1200 (USD 12) per beneficiary per year for basic care facilities a(Level 3 and 4)

KES 1400 (USD 14) per beneficiary per year for tertiary care facilities a(Level 5 and 6)

KES 1500 (USD 15) Public hospitals KES 2850 (USD 28.5) Private hospitals

KES 9500 (USD 95) per session twice weekly

KES 500000 (USD 5000)

KES 10000 (USD 100) Normal child birth

KES 30000 (USD 300) Caesarean section

KES 5000 (USD 50) for normal child birth or caesarean section

Radiotherapy

- KES 18000 (USD 180) per week

Chemotherapy

- Basic- KES 25000 (USD 250) per cycle

- Complex- KES 150000 (USD 1500) per cycle

Major surgeries

- KES 80000 (USD 800) for level 3 and 4 facilities

- KES 130000 (USD 1300) for level 5

and 6 facilities

Minor surgeries

- KES 30000 (USD 300) for level 3

and 4 facilities

- KES 40000 (USD 400) for level 5

and 6 facilities

Specialised surgeries

- KES 500000 (USD 5000)

KES 30000 (USD 300) per year

MRI capped at KES 15000 (USD

150)

CT scan capped at KES 8000 (USD 80)

Capped at KES 50000 (USD 500) per annum

Capped at KES 40000 (USD 400) per annum

Capped at KES 200000 (USD 2000)

Job group or its Annual limit equivalent

L

KES 1000000

(USD 10000)

M

KES 1250000

(USD 12500)

N 
Table 3 NHIF Provider payment methods and rates [22] (Continued)

\begin{tabular}{|c|c|c|c|}
\hline \multirow{2}{*}{$\begin{array}{l}\text { Provider } \\
\text { payment } \\
\text { method }\end{array}$} & \multirow[t]{2}{*}{ Healthcare benefit package } & \multicolumn{2}{|c|}{$\begin{array}{l}\text { Reimbursement rate } \\
1 \mathrm{USD}=100 \mathrm{KES}\end{array}$} \\
\hline & & $P$ & $\begin{array}{l}\text { KES } 1750000 \\
\text { (USD 17500) }\end{array}$ \\
\hline & & Q & $\begin{array}{l}\text { KES 2000000 } \\
\text { (USD 20000) }\end{array}$ \\
\hline & & $R, S, T$ & $\begin{array}{l}\text { KES } 2250000 \\
\text { (USD 22500) }\end{array}$ \\
\hline & $\begin{array}{l}\text { Outpatient care (curative and preventive services) for Enhanced scheme members of higher } \\
\text { job groups ( } L \text { and above or its equivalent) [14] }\end{array}$ & $\begin{array}{l}\text { Job group or its } \\
\text { equivalent }\end{array}$ & Annual limit \\
\hline & & L & $\begin{array}{l}\text { KES } 100000 \\
\text { (USD 1000) }\end{array}$ \\
\hline & & M & $\begin{array}{l}\text { KES } 150000 \\
\text { (USD 1500) }\end{array}$ \\
\hline & & $\mathrm{N}$ & $\begin{array}{l}\text { KES } 200000 \\
\text { (USD 2000) }\end{array}$ \\
\hline & & $P$ & $\begin{array}{l}\text { KES } 225000 \\
\text { (USD 2250) }\end{array}$ \\
\hline & & Q & $\begin{array}{l}\text { KES } 250000 \\
\text { (USD 2500) }\end{array}$ \\
\hline & & $R, S, T$ & $\begin{array}{l}\text { KES } 350000 \\
\text { (USD 3500) }\end{array}$ \\
\hline \multirow[t]{3}{*}{ Per diem } & $\begin{array}{l}\text { Comprehensive inpatient care (Covers medical and surgical conditions that require } \\
\text { admission) }\end{array}$ & \multicolumn{2}{|c|}{$\begin{array}{l}\text { KES 1500-4000 (USD 15-40) for } \\
\text { public (government) health facilities } \\
\text { and, low- cost private facilities and } \\
\text { mission hospitals. No co-payments. }\end{array}$} \\
\hline & $\begin{array}{l}\text { Non- comprehensive inpatient care (Covers medical and surgical conditions that require } \\
\text { admission) }\end{array}$ & \multicolumn{2}{|c|}{$\begin{array}{l}\text { KES 2000-4000 (USD 20-40) for } \\
\text { high-end private hospitals. Mem- } \\
\text { bers pay top up deficit by self-pay } \\
\text { or co-insurance }\end{array}$} \\
\hline & Foreign treatment & \multicolumn{2}{|c|}{$\begin{array}{l}\text { KES } 1700 \text { (USD 17) per day of } \\
\text { hospitalization }\end{array}$} \\
\hline
\end{tabular}

aLevel 3- Offer basic outpatient, basic maternity (obstetric) services and routine laboratory tests

Level 4- 1st referral hospitals. Offer a broader range of inpatient and outpatient care, emergency obstetric care, specialised laboratory and radiology services.

Level 5- 2nd referral hospitals. Offer more comprehensive specialised outpatient and inpatient curative services including intensive care.

Level 6- Highest level of care in the Kenyan health system. Offer highly specialised and complete set of care.

Health $(\mathrm{MOH})$ (national government) and County Department of Health (county government), 2) public and private health facilities and, 3) NHIF beneficiaries respectively. This study specifically focused on the effect of the NHIF purchasing reforms on the strategic purchasing actions involved in each of the key relationships and the implications of this on health system goals.

\section{Study sites}

We purposively selected respondents with knowledge of and experiences with NHIF since this was the phenomenon of interest in our study [33]. We selected participants at the national and county level. Participants at the national level included health financing stakeholders (policy makers, implementers) and development organizations providing technical and/or financial support to health financing initiatives in Kenya. These participants included officials from $\mathrm{MOH}$, NHIF and development partners. At the county level, we selected two counties (Table 4) with contrasting levels of socioeconomic factors, health indicators, health sector resource allocation (a proxy indicator of the importance attached to the health sector by the respective county), logistical reasons and safety assurance for the researchers. We have anonymized the counties to maintain confidentiality of the study participants.

In each county, we selected three NHIF accredited health facilities that could offer services under the new benefit packages (that is, outpatient, inpatient and specialised health services): one public first referral (Level 4), one public second referral (Level 5) and one private (level 4) facility. Permission to conduct the study in these facilities 


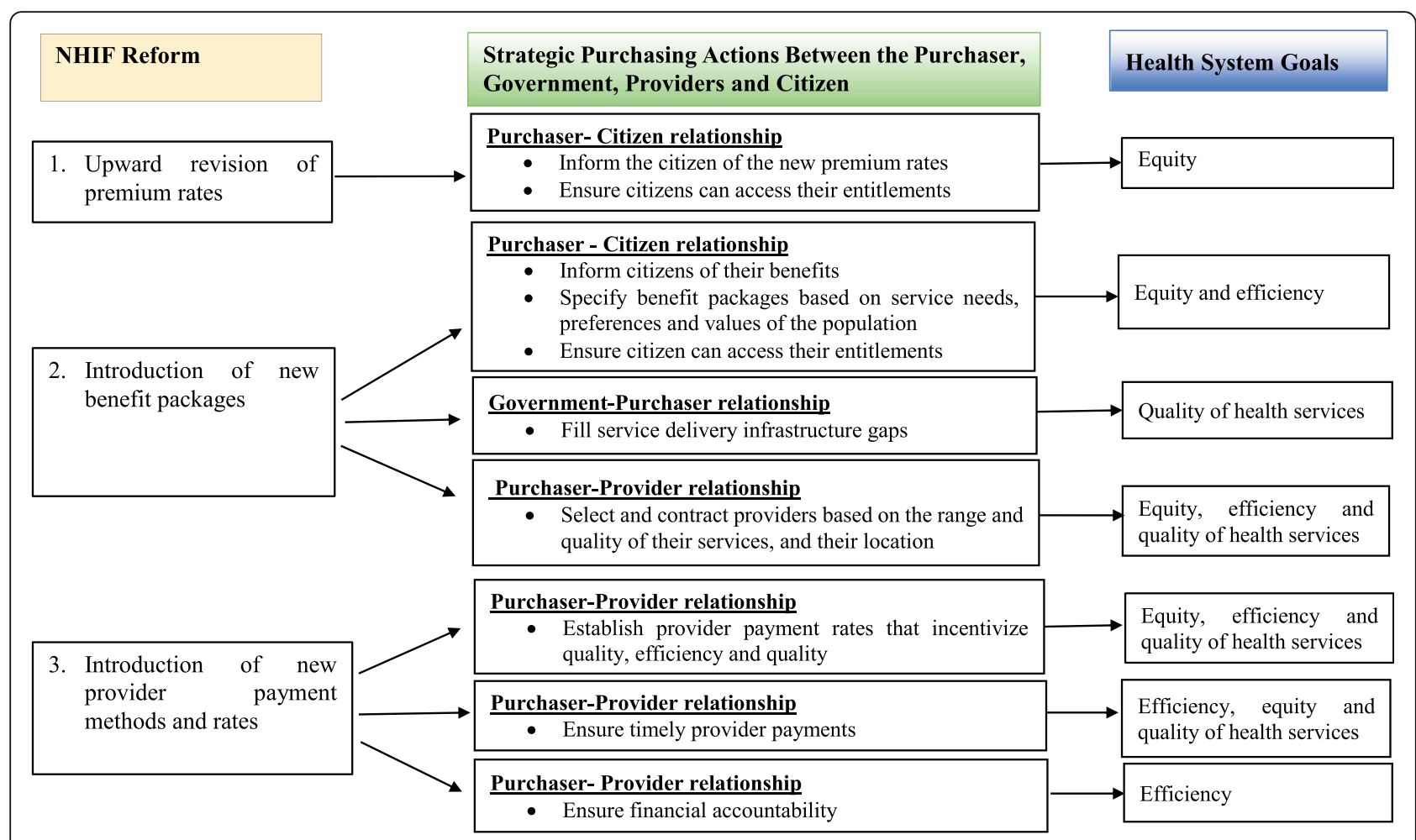

Fig. 1 Conceptual framework

was provided by the respective institutional heads. Table 5 outlines the characteristics of the selected hospitals which have been anonymized to maintain confidentiality of the study participants.

\section{Data collection}

We collected data between September and December 2017 through in-depth interviews (IDIs), focus group discussions (FGDs) and document reviews. All the participants included in this study gave written informed consent after being presented with information on the organisation conducting the study, why the study was being done and who the researchers were. Two researchers (EK and RM) conducted 41 IDIs in English with participants from the national and county levels (Table 6) using semi-structured interview guides developed from the study's conceptual framework (Fig. 1). First, we developed interview questions specific to each reform using the relevant strategic purchasing

Table 4 Characteristics of study counties

\begin{tabular}{|c|c|c|c|c|}
\hline \multicolumn{2}{|l|}{ Characteristic } & $\begin{array}{l}\text { County } \\
1\end{array}$ & $\begin{array}{l}\text { County } \\
\|\end{array}$ & Kenya \\
\hline \multicolumn{2}{|l|}{ Projected population 2015} & $\begin{array}{l}1,831 \\
800\end{array}$ & $\begin{array}{l}1,107 \\
755\end{array}$ & $44,157,000$ \\
\hline \multicolumn{2}{|l|}{ Unemployment rate } & $19 \%$ & $12.5 \%$ & $7.4 \%$ \\
\hline \multicolumn{2}{|l|}{ Poverty rate } & $21.8 \%$ & $60 \%$ & $36.1 \%$ \\
\hline \multirow[t]{2}{*}{$\begin{array}{l}\text { Distribution of health facilities by } \\
\text { ownership }\end{array}$} & $\begin{array}{l}\text { Private (for-profit and not- } \\
\text { for-profit) }\end{array}$ & $80.5 \%$ & $45 \%$ & $50.3 \%$ \\
\hline & Public & $19.5 \%$ & $55 \%$ & $49.7 \%$ \\
\hline \multicolumn{2}{|l|}{ Doctor: population ratio } & $1: 17000$ & $1: 44634$ & 1:10000 \\
\hline \multicolumn{2}{|l|}{ Immunization coverage } & $90 \%$ & $53.6 \%$ & $80 \%$ \\
\hline \multicolumn{2}{|c|}{$\begin{array}{l}\text { Percentage of County budget allocated to health (Financial Year) } \\
\text { FY 2015/16 }\end{array}$} & $32 \%$ & $22 \%$ & $\begin{array}{l}\text { Average percentage of county budget allocated to health FY } \\
2015 / 16=23.4 \% \\
\text { *Target }=35 \%\end{array}$ \\
\hline \multicolumn{2}{|c|}{ Percentage of County budget allocated to health FY 2016/17 } & $33 \%$ & $27 \%$ & $\begin{array}{l}\text { Average percentage of county budget allocated to health FY } \\
2016 / 17=25.2 \%\end{array}$ \\
\hline
\end{tabular}


Table 5 Characteristics of study hospitals

\begin{tabular}{lllllll}
\hline Characteristic & Hospital A & Hospital B & Hospital C & Hospital D & Hospital E & Hospital F \\
\hline Ownership & Public & Public & Public & Public & Private & Private \\
Level & Level 4 & Level 4 & Level 5 & Level 5 & Level 4 & Level 4 \\
County & County I & County II & County I & County II & County I & County II \\
Total annual outpatient attendance workload & 294,352 & 121,661 & 330,022 & 283,677 & 19,153 & 18,539 \\
Total annual inpatient admissions & 20,534 & 11,593 & 22,013 & 22,622 & 3366 & 1984 \\
Number of beds & 289 & 195 & 457 & 265 & 20 & 36 \\
\hline
\end{tabular}

actions as outlined in the framework. Then we developed probes relating to equity, efficiency and quality based on broader reading of literature (See Additional file 1: Semi-structured interview guide). The trustworthiness or construct validity of the semi-structured interview guide was tested by a team of health economics researchers in our research organization in Kenya who checked for ambiguities and leading questions. All IDIs were conducted at the participant's workplace and were audio-recorded using encrypted audio-recorders with consent from the participants. Each IDI lasted between 35 and $70 \mathrm{~min}$.

Two researchers (EK and RM) conducted 4 FGDs with 51 NHIF members- 2 FGDs in each county included in the study. Each FGD comprised of a total of 10-16 NHIF members, both men and women of various ages and employment status (formal and informal) as identified by regional NHIF officials and local community health volunteers. Table 7 provides a summary of these characteristics. FGDs were conducted at a location central to the participants. All FGDs were recorded in Swahili using encrypted audio-recorders with consent from the participants and lasted between 60 and $90 \mathrm{~min}$. Swahili was chosen as the medium of communication for the FGDs since community participants had varied levels of education and hence varied levels of competency in English but were all competent in Swahili. The interviewers, EK and RM, were conversant with Swahili which is Kenya's national language. Three researchers (EK, RM and EB) held face-to-face peer debriefing sessions after conducting IDIs and FGDS to critique the data collection process, identify areas that needed further probing and to discuss the emerging themes [34]. We stopped data collection once saturation- point of no new information [35]was reached in both the IDIs and the FGDs.

Table 6 Summary of study respondents

\begin{tabular}{|c|c|c|c|c|c|}
\hline \multicolumn{6}{|l|}{ National level respondents } \\
\hline & \multicolumn{2}{|l|}{ Male } & \multicolumn{2}{|c|}{ Female } & Total \\
\hline Ministry of Health & \multicolumn{4}{|l|}{1} & 1 \\
\hline NHIF & \multicolumn{2}{|l|}{1} & \multicolumn{2}{|l|}{1} & 2 \\
\hline Development partners & \multicolumn{2}{|l|}{3} & \multicolumn{2}{|l|}{1} & 4 \\
\hline \multirow[t]{2}{*}{ Total national level participants } & \multicolumn{2}{|l|}{5} & \multicolumn{2}{|l|}{2} & 7 \\
\hline & \multicolumn{2}{|c|}{ County I } & \multicolumn{2}{|c|}{ County II } & Number \\
\hline County level participants & Male & Female & Male & Female & Total \\
\hline $\begin{array}{l}\text { County health department officials (County director of health, County nursing officers, county clinical } \\
\text { officers) }\end{array}$ & 1 & 1 & 1 & 2 & 5 \\
\hline NHIF branch officials & 2 & 1 & 1 & 1 & 5 \\
\hline $\begin{array}{l}\text { Public hospital managers (Medical superintendent, Nursing services managers, Pharmacist in-charge, Clin- } \\
\text { ical officer in-charge) }\end{array}$ & 1 & 2 & 2 & 2 & 7 \\
\hline Private hospital managers (Medical managers, Nursing services managers) & 1 & 1 & - & 1 & 3 \\
\hline Public hospital frontline health workers (Clinical officers, Nurses) & 1 & 1 & 1 & 1 & 4 \\
\hline Private hospital frontline health workers (Clinical officers, Nurses, pharmacists) & 1 & 2 & 1 & 2 & 6 \\
\hline Public hospital NHIF billing clerks & - & 1 & 1 & - & 2 \\
\hline Private hospital accounts staff & 1 & & - & 1 & 2 \\
\hline Total county level participants & 8 & 9 & 7 & 10 & 34 \\
\hline
\end{tabular}


Table 7 Characteristics of FGD participants

\begin{tabular}{|c|c|c|c|c|}
\hline \multirow[t]{2}{*}{ Attribute } & \multicolumn{2}{|l|}{ County I } & \multicolumn{2}{|l|}{ County II } \\
\hline & FGD I & FGD ॥ & FGD I & FGD ॥ \\
\hline \multirow[t]{2}{*}{ Gender } & Male $(n)=6$ & Male $(n)=7$ & Male $(n)=4$ & Male $(n)=5$ \\
\hline & Female $(n)=6$ & Female $(n)=9$ & Female $(n)=6$ & Female $(n)=8$ \\
\hline Age range & $28-57$ & $31-65$ & $25-53$ & $33-67$ \\
\hline \multirow[t]{2}{*}{ Employment status } & Formal sector $(n)=9$ & Formal sector $(n)=12$ & Formal sector $(n)=8$ & Formal sector $(n)=10$ \\
\hline & Informal sector $(n)=3$ & Informal sector $(n)=4$ & Informal sector $(n)=2$ & Informal sector $(n)=3$ \\
\hline Total FGD participants $(n=51)$ & County I $(n)=28$ & & County II $(n)=23$ & \\
\hline
\end{tabular}

Lastly, we reviewed policy documents (Table 8), regulations, press releases, NHIF websites, grey and peer reviewed literature for information regarding the new reforms, their effect on NHIF's purchasing actions and health system goals of equity, efficiency and quality of health services.

\section{Data management and analysis}

All audio records from the IDIs were transcribed verbatim in English. FGDs were transcribed verbatim in Swahili and translated into English. All transcripts were reviewed for transcription accuracy by comparing them against their respective audio files. The transcripts were then imported into QSR NVIVO 10 [36] to manage coding and analysis. We used a Framework approach to analyse data. The Framework approach is an analytic process that involves a systematic process of sifting, sorting, coding and charting data into key issues and themes [37]. One researcher (RM) first familiarized herself with the data through line-by-line reading and re-reading of the transcripts. She then developed codes deductively from the study's conceptual framework and applied the codes to segments in the transcripts that were interpreted as important.
All the study team members (AH, EB, EK, KH and $\mathrm{RM}$ ) then reviewed and discussed the initial coding framework and coded data. Discrepancies in coding were discussed and reconciled appropriately before the final coding framework was approved by the study team. Two researchers [EB and RM] then applied the final coding framework to the rest of the data grouping similar codes into themes and later charted the data to allow development of meaning through comparisons and interpretations.

\section{Results}

The results are grouped in relation to each NHIF reform, and within each reform according to the relevant purchasing relationships and actions (see Fig. 1).

\section{NHIF reform 1: upward revision of premium contribution rates}

Purchaser-citizen relationship

Inadequate communication on the upward revision of premium contribution rates The NHIF employed various mass communication media to inform members of the public of the new monthly

Table 8 Documents included in the review

\begin{tabular}{|c|c|}
\hline \multirow{6}{*}{$\begin{array}{l}\text { National } \\
\text { statutory } \\
\text { documents }\end{array}$} & The Constitution of Kenya \\
\hline & Vision 2030 \\
\hline & Kenya Household Health Expenditure and Utilisation Survey. \\
\hline & Kenya Service Availability and Readiness Assessment Mapping (SARAM) Report. \\
\hline & Mini-service availability and readiness assessment (MINI-SARA) 2016 survey report \\
\hline & National Hospital Insurance Fund Act \\
\hline \multirow[t]{8}{*}{ NHIF documents } & Annual Management report 2015/16 \\
\hline & Annual Management report 2016/17 \\
\hline & Explanation of the benefit package for the National Scheme. \\
\hline & NHIF report on availability and quality of NHIF services at the healthcare provider and NHIF offices \\
\hline & Comprehensive medical insurance scheme for civil servants \& disciplined services hand book \\
\hline & Handbook For Provision Of Comprehensive Medical Cover, Group Life Insurance and Last Expense Cover to Civil Servants \\
\hline & Enhanced Benefits Medical Scheme Book \\
\hline & National Police service \& Kenya Prisons Service Comprehensive Medical Cover \& Last Expense Handbook \\
\hline
\end{tabular}


premium contribution rates, their timing, how to remit them and penalties for late payments. The channels included: television, radio, newspapers, pamphlets, the NHIF website, social media, billboards, mobile phones (short message service), and sensitization campaigns at both national and county levels. Study participants, however, felt that communication through these channels did not reach some key population groups such as the elderly, the uneducated, the unemployed, people living with disabilities (visual or hearing disabilities), the poor and the people in the rural and marginalised areas. This was blamed on limited access to these media platforms as well as limited number of NHIF service points.

"Those people in remote areas have not been reached especially where NHIF offices cover a large area. They cannot give that information immediately because it takes time for them to go and access those people and give that information" Male participant, NHIF, County I

These population groups were less likely to be aware of the new premium rates. They continued making premium payments using old rates which limited their access to the new benefit entitlements since they were no longer considered active contributors.

"At the village, some people are not aware at all of the increased premium rates and how they operate. It is only when they go to the hospital that they really get shocked that they cannot get services and they are being told to go to the NHIF office." Male Participant, FGD I, County II

Unaffordability of the increased premium rates limited access of certain citizen groups to the entitlements Study participants considered the new premium rates for the informal sector unfair and unaffordable as they were fixed over quite large income ranges. Premium contributions for the formal sector were however graduated depending on the salary range. Our review of the new premiums rates showed that they were regressive as lowincome earning population groups in both the formal and informal sectors contributed more of their income towards the premiums than higher-income earning groups (Fig. 2).

Unaffordability of the new premiums was considered a barrier to enrolment and hence a barrier to access to needed care particularly for the unemployed; those living in rural and marginalised areas; the youth of 18 years and above but not enrolled in school; the elderly; people living with disabilities and those in the informal sector with meagre and unstable earnings.

"In the village, there are youths who have finished school without formal employment but their age surpasses the required age for the cover under their parents. As a parent getting that 500 shillings to pay for him or her is a problem. They are not covered." Female participant, FGD II, County II

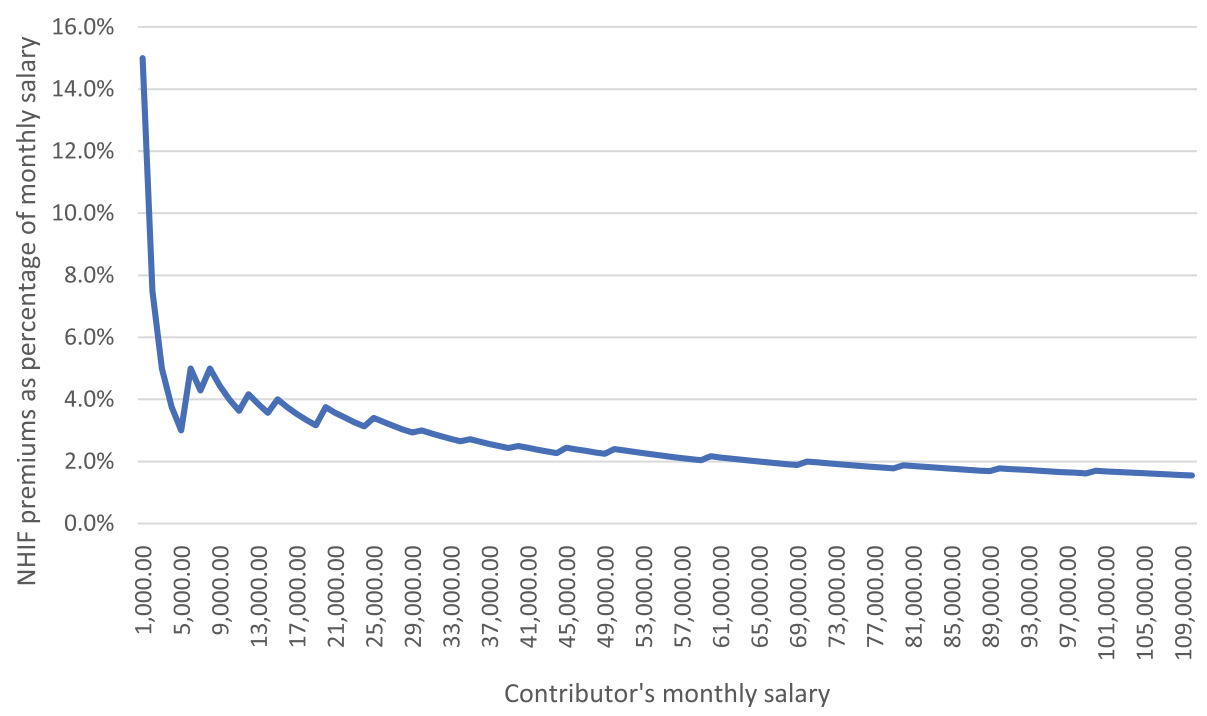

Fig. 2 Regressivity of premium contribution rates after the reforms 
"There are quite a number of people who are not taken care of like the disabled group who cannot afford to pay for the national scheme. And where do they fall? They also become sick. Unless someone pays the money for them" Male manager, private hospital $\mathrm{F}$

FGD participants working in the informal sector cited the higher premium rates as a cause of attrition as they could no longer afford them. Document reviews showed that while total NHIF membership had grown from 4 million in 2012 to 6.8 million in 2017 , only $48 \%$ of these members were active contributors [15]. Active contributors were fewer in the informal sector than formal sector. Only $27 \%$ of informal sector members had active membership compared to $65 \%$ of the formal sector members as of June 2017 [15].

"Now we are required to pay 500 shillings. This is too much money for poor people like me. I have nowhere to get that kind of money. I felt that I had no option but to abandon my card" Female participant, FGD II, County I

"NHIF is for those who can afford" Male participant, Development partner, National-level

\section{NHIF reforms 2: introduction of new benefit packages Purchaser-citizen relationship}

Inadequate communication on the new benefit packages The NHIF used the same channels used for communicating the new premium rates to provide information on the new benefit packages including how and where to access them. To access outpatient services, NHIF members and their dependents were expected to pre-select a health facility of their choice $[38,39]$ by completing a choice of outpatient medical facility form [40]. On the other hand, preselection was not required for NHIF members and their dependents to access specialised services. Just as with communication of the new premium rates, study participants felt that the elderly, uneducated, unemployed, people living with disabilities, poor and people in the rural and marginalised areas were less aware of the new benefits or where and how to access them. The lack of awareness limited their access to and utilisation of these new services. Document review showed that there was low enrolment for outpatient services with only $21 \%$ of the registered members having selected their preferred healthcare providers [22]. This was partly attributed to poor communication of the access requirements to the NHIF beneficiaries [22].

"They are not fully aware because some people will say 'I have registered under NHIF' but they do not know there is something called capitation and there are restrictions with capitation. You only go where you are capitated. They must be told categorically that with NHIF, they and their dependents must be capitated somewhere to access the outpatient services. They also do not know that for inpatient care, they can go anywhere. Even those who are capitated in this hospital think that they must come for admission in this hospital not knowing that they can also be admitted anywhere else as long as they have the cover and that they meet the category of the hospital." Male manager, Hospital F, County II

Some FGD members and development partners felt that knowledge and awareness of the new reforms by certain population groups was limited by: 1) the use of complex language (such as medical terms) to describe the services offered, 2) vagueness of the benefit package where services were presented in broad categories making it difficult for users to know what specific services they are entitled to, 3) limited geographical coverage of communication and sensitization campaigns and, 4) limited knowledge and awareness among some healthcare providers who were gatekeepers for access to these services.

"There is a problem in NHIF. They have not done communication to all health facilities that we have registered with. Sometimes you are chased away and they do not normally honour us" Male participant, FGD I, County II

The benefit packages were based on service needs, preferences and values of the population The choice of services included in the new benefit packages was informed by population health needs and preferences based on disease burden from the claims received at the NHIF office, national disease burden as indicated in national reports and strategies, and complaints and preferences provided by patient support groups and NHIF beneficiaries themselves.

"We knew the needs of our members. Some of the biggest health problems were oncology and surgeries. There was also this study on noncommunicable diseases that was done by the 
Ministry that showed that cancers, diabetes and hypertension were on the rise. We also considered information from our data, and from complaints and requests received from our members through their own groups like the Kidney care group which pushed us to include dialysis sessions." Female participant, NHIF, National level

Frontline providers and FGD participants also felt that the services offered under the new benefit packages addressed prevailing disease burden.

"Yes, people's needs are covered. Majority of our patients come here with typhoid and malaria which are covered. If somebody has hernia or needs a caesarean section, surgery can be done. Normal deliveries are also covered. If somebody needs laboratory tests, they can be done. Most of the important things that the patients need are covered." Female frontline provider, private hospital $\mathrm{F}$

"The advantage lies in the fact that we can now get treatment for life threatening ailments such as cancer, cardiovascular disease, diabetes and others" Male participant, FGD I, County I

Unequal distribution of entitlements in the new benefit packages across different population groups limited citizen's access to the entitlements While the new benefit packages were responsive to the needs of the citizens, study participants reported that civil servants and other members of the enhanced schemes received a wider range of services compared to members of the National scheme and HISP. A comparison of the benefit packages across the different NHIF schemes from document reviews showed that beneficiaries of the National scheme and HISP were not entitled to preventive health services and a few other curative services that beneficiaries of enhanced schemes receive (Appendix). These differences led beneficiaries of the National scheme to make additional OOP payments to access needed services.

"Late last year, my mother was hospitalized at the district hospital. We bought medicines daily. When we went to collect the prescribed medicines in the pharmacy, there were some classifications. There were those who were given medicines but told to pay more and those with an enhanced scheme who got medicines for free. This disparity brought a lot of problems because you see your next neighbour, who is a patient like you, being served while you cannot get the same medicines without buying them." Female participant, FGD I, County II

\section{Government- purchaser relationship}

Presence of service delivery infrastructure gaps for the new benefit packages in public healthcare facilities While the new reforms included new benefit entitlements, they were not accompanied by reforms on infrastructure improvement. Study participants reported that contracted public hospitals, particularly in rural and marginalised areas, lacked appropriate service delivery infrastructure for the outpatient and special benefit packages in terms of medical equipment, medicines and human resources (medical officers, specialists and nurses). A review of the service availability and readiness assessment reports supported these claims as they highlighted the limited availability of: 1) essential medicines [41], 2) laboratory supplies [42] and, 3) specialised services such as dialysis, chemotherapy, radiotherapy and organ transplants [42] in public hospitals.

"There is a shortage of doctors and specialists like oncologists. Public hospitals are also overstretched and they do not have tests such as CT Scan or ultrasound which forces you to seek care in a private hospital. So, in as much as you have an NHIF card, it is not very useful in a public hospital because you will not get the services." Female participant, FGD II, County I

\section{Purchaser- provider relationship}

Selection and contracting of providers was characterized by a pro-urban and pro-private distribution To increase access to the new benefit packages, the NHIF embarked on a drive to expand the network of healthcare facilities to contract with. Between 2013 and 2017, the number of contracted healthcare facilities (both public and private) increased from 1237 to 5258. Study respondents reported that most of the contracted health facilities within their counties were found in the urban and peri-urban areas, particularly private hospitals, which created greater geographical inequalities in access for the people living in rural and marginalised areas.

"NHIF historically was only covering hospitals and we know that in terms of facility density, most of the facilities in rural areas are primary level so already there is a disproportion there. Even with the hospitals, 
it was a specific set of them. Not all hospitals were NHIF accredited. Now they have started going to the primary level facilities but not all of them have been brought on board. Therefore, access to care in rural areas is much lower than in urban centres and we know that the larger proportion of our population lives in rural areas." Female participant, Development partner, National-level

Document review showed that private health facilities (both private-for-profit and private-not-for-profit) accounted for 75.5 and $56.9 \%$ of all health facilities contracted by NHIF in County I and II, respectively. While this finding may be expected for county I which has a higher proportion of private health facilities, it was not expected for county II which had a higher proportion of public than private health facilities. NHIF officials felt that this resulted from a lack of initiative by government health facilities to seek contracts with NHIF as well as staff shortages within NHIF to do active follow up on the same.

"Private hospitals are more. It is only when we started the government initiative of Linda mama [free maternity programme] that we brought in so many government health facilities. However, it is not easy to bring them on board because they are not motivated even to come here. It is us to communicate with them, call them for letters or deliver those letters to them which is not easy. But for private facilities, it is a selfinitiative." Female participant, NHIF branch official, County II

FGD participants felt that the pro-private distribution of contracted health facilities within their counties was discriminatory because it was mainly civil servants who could access services in these facilities. Access to the health facilities varied by type of scheme. Members of the national scheme accessed services from contracted public facilities or low-cost private hospitals. Civil servants and members of enhanced schemes could access both contracted public and private health facilities including high cost private hospitals $[14,16,18]$. In addition, FGD participants felt that services offered in private-for-profit hospitals were more expensive than in the public hospitals which put them at risk of making additional OOP payments or depleting the limits capped on specialized services by the NHIF.

"I took my son to a private hospital where he was diagnosed with ulcers caused by H. pylori. His medicines cost almost 14,000 shillings. I panicked because I knew we would exhaust our yearly allocations. I also developed the same problem but I went to the Level 5 public hospital. The treatment did not cost me more than 800 shillings. I even argued with the doctor about this. How comes my son's $H$. pylori kits cost 14,000 in the private hospital but it cost me less than a thousand shillings in a public hospital? This is very bad" Male participant, FGD I, County I

\section{NHIF reforms 3: introduction of new provider payment methods and rates \\ Purchaser- provider relationship}

The new provider payments did not incentivize equity, efficiency and quality healthcare service provision due to perceived inadequacy in payment rates Both public and private providers indicated that the capitation rates offered for outpatient services were inadequate as they did not take into consideration the actual costs of services or the number of times an NHIF beneficiary would visit a health facility. NHIF officials reported that the capitation rate was informed by consultations with bodies representing both public and private providers and, findings from actuarial analysis and costing studies. However, officials from development partners, county department of health and county health facilities reported not being involved or even aware of any actuarial costing studies.

"I remember being in those discussions a while back where we were asking NHIF officials what the basis for the capitation was. They kept saying that they had done some costing studies but they never shared any of that information. We wanted to know the basis of going from 2,850 shillings for the civil servants to 1,200 shillings for the national scheme. I mean at least for the reimbursements for the special packages they could go and observe what the market rates are, right?" Female participant, Development partner, National-level

The perceived inadequacy of capitation incentivized some public providers to ask patients, particularly those with chronic illness, to buy medication elsewhere. For private providers, it incentivised them to either undertreat, charge co-payments, refer to other accredited health facilities or, admit NHIF beneficiaries who would have otherwise just required outpatient care. Media reports indicated that major private hospitals had altogether rejected capitation which further limited access to care for 
members of the national scheme [43, 44]. Healthcare providers did not understand that capitation refers to a fixed amount of money paid per patient per unit of time based on population level data on costs and average utilization of services.

"For fee-for-service, we can do more laboratory tests compared to the national scheme. For national scheme, I am told not to send them to the laboratory for many investigations because their capitation money will be exhausted just from consultation without even medication. So, I am forced to treat clinically yet some patients require a conclusive test that will help us manage them well. Yes, we are forced to cut on cost." Male frontline provider, private hospital $\mathrm{F}$

Provider payments were not timely According to public and private hospital managers, the NHIF did not make timely payments to providers for the provision of services outlined in its benefit packages including the new outpatient and specialised services. In policy, capitation for outpatient services was to be paid before service delivery (at the beginning of each fiscal quarter) while payments for inpatient and specialised services were to be reimbursed within 14 working days following submission of claims data [45]. In practice however, NHIF disbursed capitation in the middle of the fiscal quarter and took between 2 and 3 months to honour and reimburse claims for inpatient and specialised services. This was attributed to the manual claim process that was demanding, the limited number of NHIF claims and benefits officers, and reports of limited financial resources within the NHIF.

"So even claims that we took two months ago have not been reimbursed because they are down financially. The NHIF informed us that they do not have money" Male manager, public hospital C, County II

NHIF beneficiaries seeking care in private facilities felt that the delayed reimbursements by NHIF had incentivized providers to: 1) introduce co-payments, 2) deny or ration services offered to them, 3) treat them with less respect, or 4) expose them to longer waiting times than patients with other forms of insurance or cash paying patients.

"Private hospitals do not treat us with respect. There is even a notice, "do not give these medicines to NHIF patients" in their pharmacy. If you peep inside, you will see the label. It is as if you are a second-class citizen from those with other medical covers who are treated superiorly." Female participant, FGD II, County II

"It is like torture there because those who have cash are treated quickly. So, at times when I go to the hospital, I feel that it is better for me to use cash than to use my NHIF card so that I can get treatment faster." Female participant, FGD II, County I

Weak financial accountability led to fraud by healthcare providers, NHIF officials and NHIF beneficiaries Respondents reported various cases of fraudulent behaviour for financial gains by healthcare workers, NHIF officials and NHIF beneficiaries- a finding that was supported by various media reports [46-48].

"There has been massive fraud. Some of the providers are working with people at the NHIF to defraud NHIF and one of the areas they have been taking advantage of is the issue of major surgery and minor surgery. Most hospitals have been converting the minor surgeries to major surgeries so that they can get higher reimbursement. The fraud has been there but it has become a big issue since the introduction of those specialised packages" Male participant, Development partner, national-level

Several system weaknesses had led to this. First, the self-assessment process- whereby health facilities could assess their own structural capacity prior to contracting [49]- created a loophole for fraudulent behaviour. County officials reported that some providers exaggerated their structural capacity (e.g. beds, medical equipment and theatre rooms) during this process to obtain a higher level of reimbursements from per diem and case-based payments for inpatient and specialised services respectively.

"When we looked at the facility, they did not have a theatre yet NHIF said they were making claims for operations done. So how did they do the operations without the theatre? It was questionable. There was a room that they said was a theatre but we know that a theatre is not just a room. The facility did not have all the things required to make a theatre" Male county level manager, County I 
Secondly, the limited number of NHIF officials (claims and benefits officers, and quality assurance officers) undermined frequent surveillance of health facilities. Their limited number coupled with the manual claim confirmation and reimbursement process and increased workload, created a barrier to a fast and efficient process of confirming the authenticity of claims.

"Surveillance should be done at least twice a week but we face challenges. There are many contracted health facilities and fewer quality officers so it is not easy for us to reach all of them. So now we do what we call smart surveillance- where we visit health facilities with high claim notifications" Female NHIF branch official, County II

Thirdly, weak identification processes for NHIF beneficiaries seeking care incentivized some beneficiaries to engage in fraudulent behaviour such as: 1) use of false identity cards to obtain care, 2) hiring out of the NHIF cards to those without but who needed access to care, 3) use of NHIF cards to illegally obtain medication for people who were not members of the scheme or, 4) impersonation.

"The challenge we have in government (public) facilities is actually that of fraud through impersonation where one gives their card to their sibling to pass as them in order to use the card to access services" Male NHIF branch official, County I

NHIF officials and media reports indicated that the NHIF was however implementing various strategies to curb fraudulent activities such as: online notifications for inpatient admissions, centralised authorisation (letters of undertaking) for surgical procedures and specialised imaging studies [50] and, introduction of biometrics for identification of beneficiaries.

"We are going the biometric way. We assessed and provided some health facilities with the gadgets and software. Once we have all the biometric features for the members, we will reduce cases of impersonation and cases of patients not being in the wards when they were supposedly admitted." Male NHIF branch official, County II

\section{Discussion}

In this study, we set out to examine how the recent reforms of the NHIF affected its purchasing practices. Our study findings show that even with the new reforms, the NHIF remains a passive purchaser with negative implications for equity, efficiency and quality arising from weaknesses in either the design or implementation of the reforms.

\section{Equity implications}

First, the higher premium rates were unaffordable and regressive for the poor, elderly, people living with disabilities, unemployed and informal sector workers with meagre and unstable earnings. This policy design created a financial barrier to enrolment and led to attrition. Affordability of premium contributions has been shown to affect enrolment and retention in other LMIC settings such as Ghana [5153], Uganda [54], Burkina Faso [55] and Nigeria [56]. In Ghana, informal sector contributions were found to be particularly regressive [57]. Second, differences in the benefit package between the national scheme and enhanced schemes, a policy design issue, led to inequities in access to services and OOP payments for the services not covered. Differences in benefit package design lead to differences in financial protection where generous benefit packages are associated with lower OOP payments $[58,59]$. Third, limited awareness of the new benefits and premiums by the poor, elderly, unemployed, informal sector workers, people in the rural areas and those with disabilities due to varying access to mass media and NHIF service points, a policy implementation issue, led to variations in enrolment, access to care and unnecessary OOP payments. Studies in Nigeria, Burkina Faso, Kenya and Ghana have shown that awareness of insurance schemes affects participation and enrolment $[56,60-62]$ as well as service utilisation among enrolees as seen in India [63]. A guiding principle for purchasers is that communication of UHC-inspired reforms should inform the population of their entitlements and obligations [2,64] through public provision of detailed but simplified information on included and excluded services and the associated levels of OOPs [30, 65]. This empowers beneficiaries, particularly marginalised groups, to claim their benefits and entitlements and improves utilisation among these population groups [30]. It also provides one of the best strategies to reduce possible variations in access to care [65] and informal or OOP payments by beneficiaries to providers $[65,66]$. A fourth factor undermining equity was the pro-urban and pro-private distribution of contracted health facilities. This policy implementation issue undermined access for the poor and those living in rural and marginalised areas who are known to have higher burden of disease and limited financial protection [67] which predisposes them to catastrophic health expenditures [68]. In Kenya, $65.3 \%$ of rural populations depend on public health 
facilities for outpatient services [69]. In fact, private hospitals (both for-profit and not-for-profit) have been shown to be pro-rich [70]. Decisions to increase coverage should therefore give priority to these groups $[4,30]$ and to the public sector by ensuring that it is well-funded and well- structured with adequate service delivery infrastructure [4, 71]. Lastly, perceived inadequacy of, and delayed NHIF reimbursements, a policy implementation issue, led to preferential treatment of privately insured and/ or uninsured cash-paying patients over NHIF beneficiaries particularly in private hospitals. The provider incentives embodied in payments systems influence provider behaviour in treatment decisions which in turn affect equity in access to needed services, quality and efficiency of service provision $[8,72]$.

\section{Efficiency implications}

We identified two main implications for efficiency. First, unnecessary admissions and referrals due to perceived inadequacy of capitation rates, a policy design and implementation issue, compromised efficiency since resources were spent on unnecessary care. Second, weak accountability mechanisms, a policy implementation issue, compromised efficiency through loss of resources to fraudulent activities. Unnecessary hospital admissions and fraud are among the top ten causes of inefficiency in health systems globally [3].

\section{Quality implications}

Quality of care particularly in public hospitals was compromised by lack of accompanying reforms on quality and infrastructure improvement- a weakness in the design and implementation of the new policies. High quality care requires skilled health workers, well-equipped hospitals and reliable medicines [73] that are equitably distributed to promote equitable access to services in the benefit package [5]. Reforms of benefit packages should also inform infrastructure developments $[30,65]$, failure to which makes the benefit package merely a wish list, with limited access to actual services and limited financial risk protection [65]. Quality was also compromised by rationing of services to patients due to perceived low provider payment rates and delayed reimbursements which are both weaknesses in the design and implementation of the new policies.

\section{Recommendations}

Drawing from these findings, we recommend that policy makers at the national and county governments as well as the NHIF, address weaknesses in the design and implementation of the reforms for them to be successful.

The National and county governments should improve the infrastructural capacity of public healthcare facilities to support the UHC- inspired NHIF reforms. This includes priority attention to human resource for health, medicines, and medical equipment. They should also find innovative ways of financing premiums for the poor, elderly, people with disabilities, unemployed and those in the informal sector in a bid to leave no one behind. This can be done through specific allocation of general government revenue.

For its part, the NHIF should first, re-orient its facility selection to create a balance between public and private facilities, and between urban and rural facilities to improve geographical access. Second, engage healthcare providers in determining provider payment rates and publicly avail information on how the rates are developed. This will improve provider acceptance. Third, actively educate health workers on the services offered in the benefit package as they are the gatekeepers who provide access to health services. Fourth, ensure timely reimbursements to healthcare facilities to send the correct incentives for service delivery. Fifth, invest in fraud minimization strategies such as verification of provider self-assessments reports and claims as well as enrolee membership. This can be implemented by using a riskbased approach to sample facilities for physical verification of self-assessment reports and imposing tough sanctions for providers that are found to present fraudulent self-assessment reports and for those enrolees and providers engaging in fraud. Sixth, harmonize its benefit packages into one benefit package for all its members to reduce inequities in access to needed services. Seventh, simplify the language used in communication of the benefit packages and adopt communication strategies that reach low-income, less educated, rural population groups such as visits to homes and public places such as markets and places of religious worship. Lastly, the NHIF should strengthen monitoring and supervision of healthcare providers and impose sanctions and rewards for quality of care provided.

\section{Conclusion}

Our study shows that while the new reforms sought to expand population and service coverage and reduce OOP, the NHIF remains a passive purchaser due to weaknesses in the design and implementation of the reforms. These weaknesses affected its purchasing actions with negative implications for the health system goals of equity, efficiency and quality. For the reforms to accelerate the country's progress towards $\mathrm{UHC}$, policy makers from the government (both national and county) as well as the NHIF should put deliberate efforts to align the design and implementation of such reforms with strategic purchasing actions that are aimed at improving equity, efficiency, and quality of health system delivery. 


\section{Appendix}

Table $\mathbf{9}$ Comparison of the benefit packages across schemes

\begin{tabular}{|c|c|c|c|}
\hline Services & \multicolumn{2}{|c|}{$\begin{array}{l}\text { Enhanced schemes: (Civil servants and disciplined services scheme; } \\
\text { County schemes, National Police Service and Kenya Prisons Service } \\
\text { Medical Scheme }[15,18-20] \text { ) }\end{array}$} & National scheme and HISP [23] \\
\hline \multirow[t]{26}{*}{ Outpatient } & \multicolumn{2}{|l|}{ Consultation } & Consultation \\
\hline & \multicolumn{2}{|c|}{ Laboratory investigations } & Laboratory investigations \\
\hline & \multicolumn{2}{|l|}{ Drug administration } & Drug administration \\
\hline & \multicolumn{2}{|c|}{ Radiological examinations (basic x-rays) } & Radiological examinations (basic $x$-rays) \\
\hline & \multicolumn{2}{|c|}{ Nursing and midwifery services } & Nursing and midwifery services \\
\hline & \multicolumn{2}{|c|}{ Minor surgical procedures } & Minor surgical procedures \\
\hline & \multicolumn{2}{|c|}{ Rehabilitation services } & rehabilitation services \\
\hline & \multicolumn{2}{|c|}{ Referral for specialised services } & Referral for specialised services \\
\hline & \multirow[t]{8}{*}{ Dental care: } & Dental consultation & Dental consultation \\
\hline & & Extractions & Extraction only \\
\hline & & $\begin{array}{l}\text { Surgical extractions (including doctors' fees } \\
\text { and theatre costs) }\end{array}$ & \\
\hline & & Root canal & \\
\hline & & Orthodontics & \\
\hline & & Dental Filling & \\
\hline & & $X$-rays & \\
\hline & & Dentures & \\
\hline & \multicolumn{3}{|l|}{ Optical services } \\
\hline & \multirow[t]{5}{*}{ Vaccinations } & KEPI vaccines & \multirow[t]{5}{*}{ KEPI vaccines } \\
\hline & & Rota virus vaccine & \\
\hline & & Anti-rabies & \\
\hline & & Anti-Snake venom & \\
\hline & & yellow fever vaccine & \\
\hline & \multirow{2}{*}{$\begin{array}{l}\text { Emergency rescue } \\
\text { services: }\end{array}$} & Local road ambulance & \multirow[t]{4}{*}{ Local road ambulance } \\
\hline & & Emergency air rescue & \\
\hline & \multicolumn{2}{|c|}{$\begin{array}{l}\text { Annual medical check-up } \\
\text { i. Body mass index } \\
\text { ii. Full Haemogram } \\
\text { iii. Cholesterol } \\
\text { iv. Blood sugar } \\
\text { v. Gamma GT } \\
\text { vi. Urinalysis } \\
\text { vii. PSA (Prostate Specific Antigen for Men above 40) } \\
\text { viii. Pap smear for all women } \\
\text { ix. Mammogram }\end{array}$} & \\
\hline & \multicolumn{2}{|l|}{ Optical care } & \\
\hline \multirow{9}{*}{$\begin{array}{l}\text { Specialized } \\
\text { services }\end{array}$} & \multicolumn{2}{|l|}{ Renal dialysis } & Renal dialysis \\
\hline & \multicolumn{2}{|c|}{ Kidney care package (Renal dialysis and renal transplant) } & Kidney care package (Renal dialysis and renal transplant) \\
\hline & \multicolumn{2}{|c|}{ Rehabilitation package: drug and substance abuse } & Rehabilitation package: drug and substance abuse \\
\hline & \multicolumn{2}{|c|}{ Oncology: chemotherapy and radiotherapy } & Oncology: chemotherapy and radiotherapy \\
\hline & \multicolumn{2}{|c|}{ Radiology: MRI, CT scan } & Radiology: MRI, CT scan \\
\hline & \multicolumn{2}{|c|}{ Chronic illness: diabetes and hypertension } & Chronic illness: diabetes and hypertension \\
\hline & \multicolumn{2}{|c|}{ Surgical services (Major and minor) } & Surgical services (Major and minor) \\
\hline & \multicolumn{2}{|c|}{ Specialised laboratory tests } & Specialised laboratory tests \\
\hline & \multicolumn{2}{|c|}{$\begin{array}{l}\text { Overseas treatment for conditions that warrant treatment not } \\
\text { available in Kenya }\end{array}$} & $\begin{array}{l}\text { Overseas treatment for conditions that warrant treatment } \\
\text { not available in Kenya }\end{array}$ \\
\hline
\end{tabular}


Table 9 Comparison of the benefit packages across schemes (Continued)

\begin{tabular}{|c|c|c|}
\hline \multirow[t]{6}{*}{ Services } & $\begin{array}{l}\text { Enhanced schemes: (Civil servants and disciplined services scheme; } \\
\text { County schemes, National Police Service and Kenya Prisons Service } \\
\text { Medical Scheme }[15,18-20])\end{array}$ & National scheme and HISP [23] \\
\hline & Intensive care and High Dependency Unit & \\
\hline & Last expense cover & \\
\hline & In vitro fertilization & \\
\hline & Hearing aids & \\
\hline & Prosthetics & \\
\hline
\end{tabular}

\section{Supplementary information}

Supplementary information accompanies this paper at https://doi.org/10. 1186/s12939-019-1116-x

Additional file 1: Appendix 1. Semi- structured topic Guide for indepth interviews.

\section{Abbreviations}

CT: Computerized tomography; FGDs: Focus group discussions; FY: Financial Year; IDIs: In-depth interviews; KES: Kenya shillings; $\mathrm{MOH}$ : Ministry of Health; MRI: Magnetic Resonance Imaging; NHIF: National Hospital Insurance Fund; OOP: Out-of-pocket; RESYST: Resilient and Responsive Health Systems; UHC: Universal Health Coverage; USD: United States Dollars

\section{Acknowledgements}

Not applicable.

\section{Authors' contributions}

$\mathrm{EB}, \mathrm{KH}, \mathrm{AH}$, conceptualized the study. EB and RM developed the protocol and interview guides. EK and RM collected the data. RM developed the coding framework that was reviewed by EB. RM analysed and interpreted the data. RM prepared the first draft that was subsequently reviewed and revised by all the authors. All authors read and approved the final manuscript.

\section{Funding}

Rahab Mbau, Evelyn Kabia, Ayako Honda, Kara Hanson, and Edwine Barasa are members of the Consortium for Resilient and Responsive Health Systems (RESYST). This document is an output from a project funded by the UK Aid from the UK Department for International Development (DFID) for the benefit of developing countries.

\section{Availability of data and materials}

The datasets generated and/or analysed during the current study are not publicly available as they contain information that could potentially compromise the privacy and confidentiality of the study participants but are available from the corresponding author (RM) on reasonable request.

\section{Ethics approval and consent to participate}

We received ethical review and approval from the Kenya Medical Research Institute, Scientific and Ethics Research Unit (KEMRI/ SERU) under number SSC NO: 2795. We also obtained approval from the National Commission for Science, Technology and Innovation (NACOSTI) and relevant organizational heads followed by written informed consents from all the participants who agreed to participate in the study.

\section{Consent for publication}

All participants provided written consent for participating and granted permission to use their data publicly.

\section{Competing interests}

The authors declare that they have no competing interests.

\section{Author details}

${ }^{1}$ Health Economics Research Unit, KEMRI Wellcome Trust Research Programme, P.O. BOX 43640-00100, Nairobi, Kenya. ${ }^{2}$ Sophia University, Chiyoda City, Japan. ${ }^{3}$ London School of Hygiene and Tropical Medicine, London, UK. ${ }^{4}$ Nuffield department of medicine, Oxford University, Oxford, UK.

Received: 27 May 2019 Accepted: 23 December 2019

Published online: 03 February 2020

\section{References}

1. Lagomarsino G, Garabrant A, Adyas A, Muga R, Otoo N. Moving towards universal health coverage: health insurance reforms in nine developing countries in Africa and Asia. Lancet. 2012;380:933-43.

2. What is strategic purchasing for health? Health financing research theme, Resilient and responsive health systems (RESYST) [http://resyst.lshtm.ac.uk/ sites/resyst.lshtm.ac.uk/files/docs/reseources/Purchasing\%20brief.pdf].

3. World Health Organization: Health systems financing: the path to universal coverage. 2010; pp. 128.

4. Cotlear D, Nagpal S, Smith O, Tandon A, Cortez R. Going universal: how 24 developing countries are implementing universal health coverage from the bottom up. Washington, DC: World Bank Publications; 2015.

5. World Health Organization. Sustainable health financing, universal coverage and social health insurance. In World Health Assembly Resolution, vol. 58; 2005.

6. World Health Organization: The world health report 2000: Health Systems: improving performance.; 2000.

7. Kutzin J. A descriptive framework for country-level analysis of health care financing arrangements. Health Policy. 2001;56:171-204.

8. Kutzin J, Yip W, Cashin C. Alternative financing strategies for universal health coverage. In: World Scientific Handbook of Global Health Economics and Public Policy, vol. 1: The Economics of Health and Health Systems. Singapore: World Scientific; 2016. p. 267-309.

9. Speech by his excellency Hon. Uhuru Kenyatta, C.G.H., president and commander in chief of the defence forces of the Republic of Kenya during the 2017 Jamhuri day celebrations at the Moi International Sports Centre, Kasarani on the 12th of December 2017 [http://www.president.go.ke/201 7/12/12/speech-by-his-excellency-hon-uhuru-kenyatta-c-g-h-president-andcommander-in-chief-of-the-defence-forces-of-the-republic-of-kenya-duringthe-2017-jamhuri-day-celebrations-at-the-moi-international/].

10. Kazungu JS, Barasa EW. Levels, distribution and correlates of health insurance coverage in Kenya. Tropical Med Int Health. 2017:22:1175-85.

11. Republic of Kenya: National Hospital Insurance Fund Act, Chapter 255. 2012.

12. NHIF profile [http://www.nhif.or.ke/healthinsurance/uploads/NHIF_Profile.pdf].

13. National Hospital Insurance Fund: Comprehensive medical insurance scheme for civil servants and disciplined services handbook. 2012.

14. National Hospital Insurance Fund. Handbook for provision of comprehensive medical cover, group life insurance and last expense cover to civil servants: Nairobi; 2017.

15. National Hospital Insurance Fund: Annual management report as at 30th June 2017. 2017.

16. National Hospital Insurance Fund. Enhanced benefits medical scheme handbook. Nairobi; 2017

17. National Insurance Fund: National Police Service \& Kenya Prisons Service Medical Scheme. 2017

18. National Insurance Fund. National Police Service \& Kenya Prisons Service Comprehensive Medical Cover \& last expense cover. Nairobi: National Hospital Insurance Fund; 2017. 
19. Orido G, Adhiambo M: President launches Sh4b NHIF cover for students in public secondary schools. In Standard Digital; 2018.

20. National Hospital Insurance Fund. EduAfya towards Universal Health Coverage, vol. 2018. Nairobi; 2018.

21. National Hospital Insurance Fund: Explanation of the benefit package for the National Scheme. 2015.

22. National Hospital Insurance Fund: Annual management report as at 30th June 2016. 2016.

23. Munge K, Mulupi S, Chuma J: A critical analysis of the purchasing arrangements in Kenya: the case of the National Hospital Insurance Fund, Private and Community-based health insurance. WORKING PAPER 7. 2015.

24. Mbau R, Barasa E, Munge K, Mulupi S, Nguhiu PK, Chuma J. A critical analysis of health care purchasing arrangements in Kenya: a case study of the county departments of health. Int J Health Plann Manag. 2018;33:1159-77.

25. Munge K, Mulupi S, Barasa EW, Chuma J. A critical analysis of purchasing arrangements in Kenya: the case of the national hospital insurance Fund. Int J Health Policy Manag. 2017;7:244-54.

26. Legal notice No.14, The National Hospital Insurance Fund Act [https://kenya. eregulations.org/media/LEGAL\%20NOTICE\%20No\%2014\%20of\%202015.pdf].

27. Bozo J. COTU (central organisation of trade unions) approves rise in NHIF premiums to Sh1,700 monthly. In Business Daily. Nairobi: Nation Media Group; 2014.

28. Adhiambo M. National Health Insurance Fund releases list of new benefits. In: Standard. Nairobi: Standard Media Group; 2016.

29. Wagstaff A, Cotlear D, Eozenou PH-V, Buisman LR. Measuring progress towards universal health coverage: with an application to 24 developing countries. Oxf Rev Econ Policy. 2016;32:147-89.

30. World Health Organization. Making fair choices on the path to universal health coverage. In: Final report of the WHO consultative group on equity and universal health coverage. Geneva; 2014.

31. Yin RK. Case study research: design and methods. New Delhi: Sage publications; 2003

32. Zainal Z. Case study as a research method. In: Jurnal Kemanusiaan, vol. 5; 2007.

33. Palinkas LA, Horwitz SM, Green CA, Wisdom JP, Duan N, Hoagwood K. Purposeful sampling for qualitative data collection and analysis in mixed method implementation research. Adm Policy Ment Health Ment Health Serv Res. 2015:42:533-44.

34. Barber JP, Walczak KK. Conscience and critic: peer debriefing strategies in grounded theory research. San Diego: Annual Meeting of the American Educational Research Association; 2009.

35. Saunders B, Sim J, Kingstone T, Baker S, Waterfield J, Bartlam B, Burroughs H, Jinks C. Saturation in qualitative research: exploring its conceptualization and operationalization. Qual Quant. 2018;52:1893-907.

36. QSR International. NVIVO for MAC: NVIVO qualitative data analysis software. Version 10, vol. 2017. p. 2017.

37. Ritchie J, Spencer L. In: Alan B, Robert GB, editors. Qualitative data analysis for applied policy research. Routledge: Analyzing qualitative data; 1994.

38. Kilonzo E. NHIF tells members to choose hospitals for outpatient treatment. In Daily Nation. Nairobi: National Media Group; 2016.

39. Kajilwa G. NHIF members to pick health-care facilities. In Standard Digital. Nairobi: Standard Media Group ; 2016

40. National Hospital Insurance Fund. Choice of outpatient medical facility form. Nairobi: National Hospital Insurance Fund; 2017.

41. Ministry of Health Kenya: Kenya Service Availability and Readiness Assessment Mapping (SARAM) Report.; 2013.

42. Republic of Kenya. In: MoH K, editor. Mini-service availability and readiness assessment (MINI-SARA) 2016 survey report; 2017.

43. Otuki N: NHIF contributors still locked out of major hospitals. In Business Daily. Nairobi: Nation Media Group; 2016.

44. Wafula P. NHIF yet to strike deal with private hospitals. In: Standard Digital. Nairobi: Standard Media Group; 2016.

45. Service commitments and stakeholder obligations [http://www.nhif.or.ke/ healthinsurance/uploads/charter/Service_Commitments_And_Stakeholder_ Obligation.pdf].

46. Gitonga A. National Hospital Insurance Fund concern over medical fraud. In: Standard Digital. Nairobi: The Standard Media Group; 2017.

47. Mwere D. Detectives unearth Sh 50 billion scam at NHIF in fresh twist. In: Daily Nation. Nairobi: The Daily Nation Media Group; 2018.

48. Julie O. NHIF investigating 80 health centers over fraud claims, suspends 7 . In Capital Business. Nairobi: Capital Digital Media, Capital Group Limited; 2019.

49. National Hospital Insurance Fund: Application form for declaration as a healthcare service provider. 2017.
50. Oketch A. Key services now require NHIF approval. In: Daily Nation. Nairobi: The Nation Media Group; 2017

51. Dalinjong PA, Laar AS. The national health insurance scheme: perceptions and experiences of health care providers and clients in two districts of Ghana. Heal Econ Rev. 2012;2:13.

52. Jehu-Appiah C, Aryeetey G, Spaan E, De Hoop T, Agyepong I, Baltussen R. Equity aspects of the National Health Insurance Scheme in Ghana: who is enrolling, who is not and why? Soc Sci Med. 2011;72:157-65.

53. Alatinga KA, Fielmua N. The impact of mutual health insurance scheme on access and quality of health care in northern Ghana: the case of KassenaNankana east scheme. J Sustainable Dev. 2011:4:125.

54. Basaza R, Criel B, Van der Stuyft P. Community health insurance in Uganda: why does enrolment remain low? A view from beneath. Health Policy. 2008;87:172-84.

55. Dong H, De Allegri M, Gnawali D, Souares A, Sauerborn R. Drop-out analysis of community-based health insurance membership at Nouna, Burkina Faso. Health Policy. 2009;92:174-9.

56. Ibiwoye A, Adeleke IA. Does national health insurance promote access to quality health care? Evidence from Nigeria. In: The Geneva Papers on Risk and Insurance-Issues and Practice, vol. 33; 2008. p. 219-33.

57. Akazili J, Gyapong J, McIntyre D. Who pays for health care in Ghana? Int J Equity Health. 2011;10:26.

58. Aji B, De Allegri M, Souares A, Sauerborn R. The impact of health insurance programs on out-of-pocket expenditures in Indonesia: an increase or a decrease? Int J Environ Res Public Health. 2013;10:2995-3013.

59. Gotsadze G, Murphy A, Shengelia N, Zoidze A. Healthcare utilization and expenditures for chronic and acute conditions in Georgia: does benefit package design matter? BMC Health Serv Res. 2015;15:88.

60. Cofie P, De Allegri M, Kouyate B, Sauerborn R. Effects of information, education, and communication campaign on a community-based health insurance scheme in Burkina Faso. Glob Health Action. 2013;6:20791.

61. Kimani JK, Ettarh R, Warren C, Bellows B. Determinants of health insurance ownership among women in Kenya: evidence from the 2008-09 Kenya demographic and health survey. Int J Equity Health. 2014;13:27.

62. Kansanga MM, Asumah Braimah J, Antabe R, Sano Y, Kyeremeh E, Luginaah I. Examining the association between exposure to mass media and health insurance enrolment in Ghana. Int J Health Plann Manag. 2018;33:531-40.

63. Boyanagari M, Boyanagari VK. Perceptions and experiences of healthcare providers and beneficiaries on the national health insurance scheme of Rashtriya Swasthya Bima Yojana (RSBY) in a Taluk of south Indian state of Karnataka. Clin Epidemiol Glob Health. 2018;7:136-9.

64. Kutzin J, Witter S, Jowett M, Bayarsaikhan D. Organization WH. In: Developing a national health financing strategy: a reference guide. Switzerland: World Health Organization; 2017.

65. Glassman A, Giedion U, Sakuma Y, Smith PC. Defining a health benefits package: what are the necessary processes? Health Syst Reform. 2016;2:39-50.

66. Kutzin J. Health financing policy: a guide for decision-makers. Health financing policy paper Copenhagen. Switzerland: WHO Regional Office for Europe. 2008;24.

67. Commission on Social Determinants of Health: Closing the gap in a generation: health equity through action on the social determinants of health. Lancet. 2008;372:1661-9.

68. Barasa EW, Maina T, Ravishankar N. Assessing the impoverishing effects, and factors associated with the incidence of catastrophic health care payments in Kenya. Int J Equity Health. 2017;16:31.

69. Ministry of Health. 2013 Kenya Household Health Expenditure and Utilisation Survey. p. 2014

70. Chuma J, Maina T, Ataguba J. Does the distribution of health care benefits in Kenya meet the principles of universal coverage? BMC Public Health. 2012;12:20.

71. Sachs JD. Achieving universal health coverage in low-income settings. Lancet. 2012;380:944-7.

72. Langenbrunner J, Cashin C, O'Dougherty S. Designing and implementing health care provider payment systems: how-to manuals: World Bank Publications; 2009.

73. World Health Organization: Delivering quality health services: a global imperative for universal health coverage. 2018.

\section{Publisher's Note}

Springer Nature remains neutral with regard to jurisdictional claims in published maps and institutional affiliations. 